\title{
Influence of Freeze-Thaw Cycles on Acoustic Emission Characteristics of Granite Samples under Triaxial Compression
}

\author{
Zhandong Su $\mathbb{D}^{1,2}$ Ke Geng, ${ }^{1}$ Fubiao Zhou, ${ }^{3}$ Jinzhong Sun, ${ }^{4}$ and Huayan $\mathrm{Yu}^{5}$ \\ ${ }^{1}$ Geological Engineering Department, Institute of Disaster Prevention, Sanhe, Langfang, Hebei 065201, China \\ ${ }^{2}$ Hebei Key Laboratory of Earthquake Disaster Prevention and Risk Assessment, Sanhe, Langfang, Hebei 065201, China \\ ${ }^{3}$ Institute of Karst Geology, Chinese Academy of Geological Sciences, Guilin, Guangxi 541004, China \\ ${ }^{4}$ School of Engineering and Technology, China University of Geosciences, Beijing 100083, China \\ ${ }^{5}$ The 23rd Metallurgical Construction Group Co., Ltd. of Minmetals, Changsha 410116, Hunan, China \\ Correspondence should be addressed to Zhandong Su; szdchris@163.com
}

Received 12 January 2021; Revised 7 March 2021; Accepted 10 March 2021; Published 22 March 2021

Academic Editor: Valeria Vignali

Copyright (C) 2021 Zhandong Su et al. This is an open access article distributed under the Creative Commons Attribution License, which permits unrestricted use, distribution, and reproduction in any medium, provided the original work is properly cited.

\begin{abstract}
Understanding the acoustic emission (AE) characteristics of rocks that have undergone freeze-thaw cycling is of great significance for the use of $\mathrm{AE}$ technology to monitor the stability of rock masses in cold regions. A series of freeze-thaw cycling experiments and triaxial compression AE tests of granite samples were performed. The results show that, with an increasing number of freeze-thaw cycles, the P-wave velocity and peak AE intensity of granite show a substantial downward trend. The AE ringing counts during triaxial compression can be divided into three stages: abrupt period, calm period, and failure period. The overall change of the characteristic AE signal of granite samples that underwent different freeze-thaw cycles is the same. The AE signal during the destruction of granite occurs in clear dual dominant frequency bands. The peak frequency increases with increasing load time, and this trend becomes less clear as the number of freeze-thaw cycles increases. Overall, the peak frequency distribution tends to change from high to low with an increasing number of freeze-thaw cycles. The results provide basic data for rock mass stability monitoring and prediction, which is of great significance for engineering construction and management in cold regions.
\end{abstract}

\section{Introduction}

The rock failure process under loading is the result of the development and propagation of primary and secondary fractures and cracks. During this process, part of the strain energy of the rock is released as an elastic wave, which results in an acoustic emission (AE) [1]. By analyzing the characteristic parameters of AEs, the deformation characteristics and failure degree of rock masses can be determined, which is a nondestructive testing method used to monitor and predict engineering disasters $[2,3]$. This method is therefore suitable for real-time observation over a long term, and its high sensitivity enables the detection of active cracks long before they become visible (microcracking) [4]. Since the AE technique was first applied to the study of rock failure processes in the late 1930s, many studies have been performed, mainly focused on the AE characteristics of rock failure under different loading conditions [5-11]. Shiotani et al. proposed a criterion for classifying fracture states by installing AE sensors into the rock slope [12]. Ranjith et al. successfully detected the rock crack initiation and its damage stress threshold using an $\mathrm{AE}$ technique [13].

Rock is a natural composite material. Freeze-thaw cycles can cause water within rock to damage the internal structure of the rock and thus change its mechanical properties [14-19]. Several common techniques can be used to detect and investigate the effects of freeze-thaw damage, including scanning electron microscopy, nuclear magnetic resonance, mercury injection, and AE. Mousavi et al. studied the effect of weathering on the microstructure of schist rocks using scanning electron microscopy and found that new cracks were created in the sample bodies and their porosities increased after 75 freeze-thaw cycles [20]. Liu et al. and Jia et al. explored internal microstructural changes in rock that had 
undergone freeze-thaw cycling with nuclear magnetic resonance and concluded that the microstructure of the rock had deteriorated because of freeze-thaw damage [21-23]. Qin et al. performed a study of the pore structure of coal samples using mercury intrusion and concluded that the volume of injected mercury was positively correlated with the number of freeze-thaw cycles [24]. Zhao et al. monitored and analyzed the $\mathrm{AE}$ characteristics of submerged riprap during freeze-thaw cycles [25]. Among these methods, AE technology is a nondestructive method that can be effectively applied to explore the effects of freeze-thaw damage on the $\mathrm{AE}$ characteristics of rock masses dynamically throughout the entire loading process. Wu et al. and $\mathrm{Su}$ et al. designed experiments to study the effects of freeze-thaw cycles on $\mathrm{AE}$ characteristics and found that $\mathrm{AE}$ events and ringing counts were relatively well correlated with freeze-thaw cycles $[26,27]$. Some limitations remain, however, in understanding the $\mathrm{AE}$ characteristics of rock failure under different environmental and experimental conditions. For this work, freeze-thaw experiments were performed on granite samples with good integrity. Subsequently, triaxial compression experiments were performed, with $\mathrm{AE}$ signals monitored throughout the duration. The effects of freezethaw cycles on the $\mathrm{AE}$ characteristics of granite samples under triaxial compression are analyzed and discussed. The results provide basic data and an experimental reference for the application of $\mathrm{AE}$ monitoring and predicting the engineering stability of rock masses in cold regions.

\section{Materials and Methods}

2.1. Tested Rock. The rock samples selected for this work are unweathered granite. To ensure experimental consistency, the samples were drilled from the same large intact block of granite. Individual samples with similar longitudinal wave velocities were selected. The fresh face of the rock is pinkishred and grey-black, with massive structure. The rock comprises of approximately $50 \%$ orthoclase, $25 \%$ quartz, $20 \%$ plagioclase, and $5 \%$ mica. The grain sizes are in the range of $2-3 \mathrm{~mm}$ for orthoclase, $1.5-3 \mathrm{~mm}$ for quartz, 1-2 $\mathrm{mm}$ for plagioclase, and 1-1.5 mm for mica (Figure 1). The orthoclase is dark red, plate column shaped and has a vitreous luster. The quartz is yellow to transparent and granular, with local aggregation into clusters. The plagioclase is grey-white, plate shaped, with a glassy luster. The mica is black, flaky and exhibits pleochroism.

The granite was processed into cylindrical specimens of $50 \mathrm{~mm}$ in diameter, $100 \mathrm{~mm}$ in height, and with an endparallelism of $\pm 0.02 \mathrm{~mm}$, as specified by the International Society for Rock Mechanics standards [28]. The physical properties of the rocks are listed in Table 1.

2.2. Experimental Apparatus. A microcontrolled electrohydraulic servo press with $2000 \mathrm{kN}$ capacity was employed for the tests. The confining pressure was hydraulically applied by a triaxial cell and held constant to within $2 \%$ during loading. The confining pressure was monitored using a strain gauge pressure transducer with an accuracy of $0.1 \mathrm{MPa}$. The axial

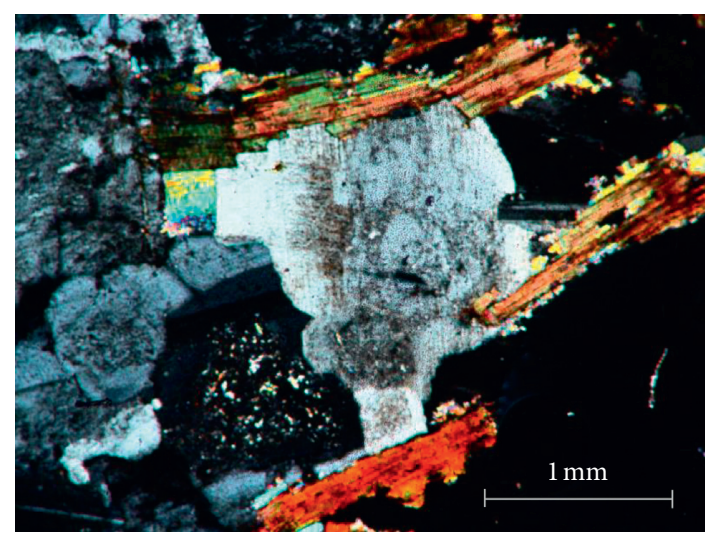

FIgURE 1: Orthogonal polarized optical photomicrograph of a sample.

loading rate was $0.01-20 \mathrm{kN} / \mathrm{s}$, the axial loading resolution was $20 \mathrm{~N}$, and the displacement loading measurement resolution was $0.001 \mathrm{~mm}$. The AE testing equipment was a full information detector (DS-5-16B, Beijing Softland Times Scientific \& Technology Co. Ltd., Beijing, China) with a sampling rate of $3 \mathrm{MHz}$, which can detect up to 16 channels simultaneously and perform multiangle continuous acquisition and automatic recordings of $\mathrm{AE}$ signals from rock samples. The preamplifier factor was $40 \mathrm{~dB}$. The $16 \mathrm{bit} \mathrm{A} / \mathrm{D}$ converter records data with a non-linear error of \pm 0.5 least significant bit (LSB). It uses an RS-2A sensor with a $150 \mathrm{kHz}$ central frequency. For the detailed amplitude-frequency responses of the $\mathrm{AE}$ sensors employed, please refer to the paper by Wu et al. [29]. The AHL800DG rapid high and low-temperature test chamber can be used in the temperature range -75 to $80^{\circ} \mathrm{C}$. The temperature deviation is $\pm 2^{\circ} \mathrm{C}$ and the temperature fluctuation is $\pm 1 \%$. A sound wave detector with a sampling interval of $0.1 \mu \mathrm{s}-50 \mathrm{~ms}$ was applied to detect the velocity of longitudinal waves in the granite samples (PDS-SW, Wuhan Yanshuxing Technology Development Co., Ltd., Wuhan, China). The receiving sensitivity is $\geq 10 \mu \mathrm{V}$.

\subsection{Experiment Plan and Procedure}

2.3.1. Experiment Plan. Fifteen granite rock samples with similar wave velocities were divided into five groups, denoted A, B, C, D, and E. Each group was then subjected to a different number of freeze-thaw cycles: $0,10,30,60$, and 90 cycles, respectively. The freezing and thawing parameters of one freeze-thaw cycle are listed in Table 2.

The temperature range of $-25^{\circ} \mathrm{C}$ to $35^{\circ} \mathrm{C}$ was selected to reflect the actual temperature range of the area in which the rock samples were drilled. The freezing period $(4 \mathrm{~h})$ and thawing period $(4 \mathrm{~h})$ were in accordance with those in previous freeze-thaw experiments [21, 22]. The duration of temperature increase indicates the time over which the temperature rises from the minimum $\left(-25^{\circ} \mathrm{C}\right)$ to the maximum $\left(35^{\circ} \mathrm{C}\right)$.

2.3.2. Experiment Procedure. Before the freeze-thaw experiment, the granite samples other than those in group A were immersed under distilled water for at least 72 hours to 


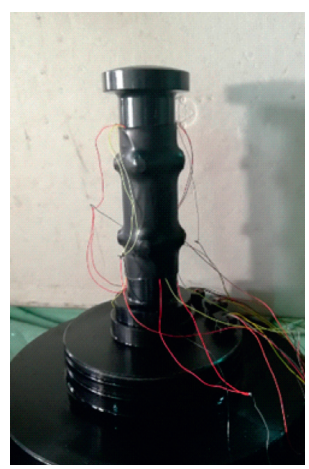

(a)

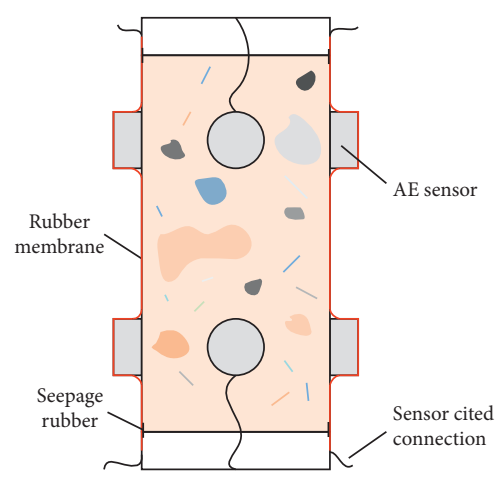

(b)

Figure 2: Sealed sample (a) and sensor assembly diagram (b).

TABLE 1: Physical properties of the granite samples.

\begin{tabular}{lccc}
\hline Water content $(\%)$ & Dry density $\left(\mathrm{g} / \mathrm{cm}^{3}\right)$ & Bulk density $\left(\mathrm{g} / \mathrm{cm}^{3}\right)$ & Wave velocity $(\mathrm{m} / \mathrm{s})$ \\
\hline 0.22 & 2.61 & 2.62 & 3670 \\
\hline
\end{tabular}

TABLE 2: Freeze-thaw parameter settings.

\begin{tabular}{lcccccc}
\hline $\begin{array}{c}\text { Minimum temperature } \\
\left({ }^{\circ} \mathrm{C}\right)\end{array}$ & $\begin{array}{c}\text { Maximum temperature } \\
\left({ }^{\circ} \mathrm{C}\right)\end{array}$ & $\begin{array}{c}\text { Time at min } \\
(\mathrm{h})\end{array}$ & $\begin{array}{c}\text { Time at max } \\
(\mathrm{h})\end{array}$ & $\begin{array}{c}\text { Duration of temp } \\
\text { increase }(\mathrm{h})\end{array}$ & $\begin{array}{c}\text { Duration of temp } \\
\text { decrease }(\mathrm{h})\end{array}$ \\
\hline-25 & 35 & 3 & 3 & 1 & 1 \\
\hline
\end{tabular}

eliminate any remaining air bubbles. After submersion, surface water was removed and the sample was weighed and sealed in plastic wrap. The sample was then placed in the freeze-thaw apparatus for the prescribed number of cycles, after which the longitudinal wave velocity was immediately measured.

Eight AE sensors were fixed on the surface of the sample with petroleum jelly and paper tape. The sensors were arranged in two sets of four, 90 degrees from each other around the circumference of the sample, with one set $15 \mathrm{~mm}$ from the top and the other $15 \mathrm{~mm}$ from the bottom. The sample was then placed into a hot shrinkable rubber jacket, with high strength antiseepage glue on the AE sensor lead wire, and installed inside the triaxial cell as shown in Figure 2. The load path was as follows: (1) the axial and confining pressures, $\sigma_{1}$ and $\sigma_{3}$, were increased synchronously to $20 \mathrm{MPa}$ at a loading rate of $0.05 \mathrm{MPa} / \mathrm{s}$. (2) The confining pressure, $\sigma_{3}$, then remains constant and the axial pressure, $\sigma_{1}$, increases at a loading rate of $0.5 \mathrm{MPa} / \mathrm{s}$.

\section{Test Results}

3.1. Frost Resistance. The frost resistance of a rock to freezethaw cycles refers to the extent of damage to the internal microstructure of the rock caused by freeze-thaw cycles. It can be quantified by changes in characteristics including weight loss (\%), changes in uniaxial compressive strength, and a decrease in P-wave velocity (\%). Here, the frost resistance of the granite samples was characterized by the decrease in measured $\mathrm{P}$-wave velocity (\%). As shown in Table 3 and Figure 3, the P-wave velocity of the granite samples decreases with the increase of freeze-thaw cycles. This is mainly because of the decrease in density caused by the expansion of cracks and the resulting damage sustained by the minerals $[30,31]$. The $\mathrm{P}$-wave velocity change $(\delta$, defined as $\left(\left(V_{0}-V\right) / V_{0}\right)$, where $V$ is the velocity after freeze-thaw cycling and $V_{0}$ is the velocity before freeze-thaw cycling) increases as the number of freeze-thaw cycles increases. Using the least-square method, the relationship between the change of P-wave velocity and the number of freeze-thaw cycles $(N)$ is obtained as follows: $N=0.098 * \delta+0.058$, with linear fitting correlation coefficient $R^{2}=0.95$.

3.2. Mechanical Properties. The differential stress $\left(\sigma_{1}-\sigma_{3}\right)$ is defined as the difference between the maximum principal stress $\left(\sigma_{1}\right)$ and the minimum principal stress $\left(\sigma_{3}\right)$. As demonstrated in Figure 4, during triaxial compression the $\left(\sigma_{1}-\sigma_{3}\right)$ axial strain $(\varepsilon)$ curve defines four stages of rock deformation: the pore compaction stage (I), elastic deformation stage (II), plastic deformation stage (II), and macroscopic failure stage (IV).

The results shown in Figure 4 indicate that damage to the internal structure of the rocks continuously develops with an increasing number of freeze-thaw cycles. Pores and fissures propagate and become interconnected, and the rock becomes looser and softer. This mainly results in two changes 
TABLE 3: P-wave velocity of the different groups before and after freeze-thaw cycling.

\begin{tabular}{lccc}
\hline Group & Velocity before freeze-thaw cycle $(\mathrm{m} / \mathrm{s})$ & Velocity after freeze-thaw cycle $(\mathrm{m} / \mathrm{s})$ & Velocity drop rate $(\%)$ \\
\hline A & 3670 & 3670 & 0 \\
B & 3620 & 3600 & 0.55 \\
C & 3730 & 3640 & 2.41 \\
D & 3680 & 3570 & 2.99 \\
E & 3650 & 3450 & 5.48 \\
\hline
\end{tabular}

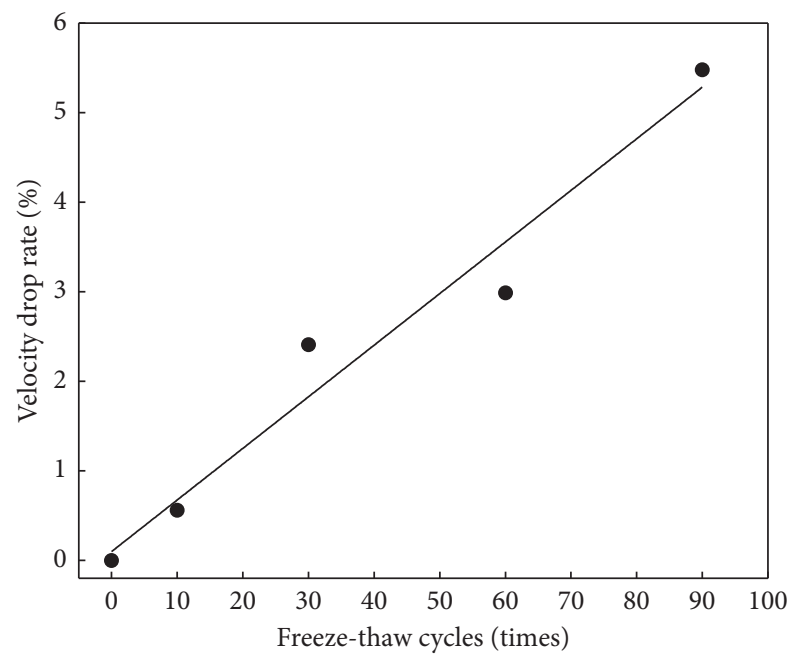

- Velocity drop rate

- Fitting line

FIGURE 3: Relationship between number of freeze-thaw cycles and measured change in wave velocity of the samples.

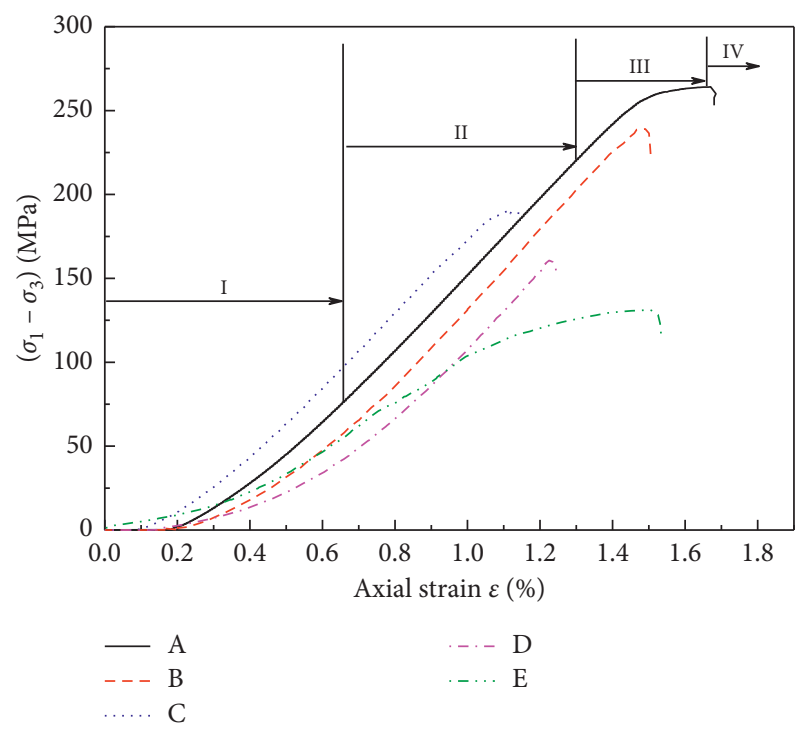

FIGURE 4: Stress-strain curve of granite samples. The four stages are highlighted with group A.

of the mechanical properties: prolonging the initial compaction stage (the concave section of the curve) and a decrease of the triaxial compressive strength (the peak value of the curve) [32].
3.3. AE Ringing Counts. The $\mathrm{AE}$ ringing counts are the number of ringing pulses that exceed the threshold of the $\mathrm{AE}$ system at a given time and are an indication of the $\mathrm{AE}$ intensity of the samples [32]. During these experiments, the discrimination threshold for AE ringing counts was set at $100 \mathrm{mV}$. Changes in $\mathrm{AE}$ ringing counts can reflect the process of fracture propagation and failure within rock in real-time. Setting a lower threshold means that some noise signals will be detected as rock failure signals.

Figure 5 illustrates changes in the $\mathrm{AE}$ ringing counts of granite samples during triaxial compression experiments. The curve of cumulative ringing counts can be obtained and the position at which the slope of the curve changes substantially was taken to be a segmented boundary. Based on this criterion, the variation in $\mathrm{AE}$ ringing counts of granite samples that have undergone freeze-thaw cycles can be divided into three stages: the abrupt period (AP), calm period (CP), and failure period (FP). The $\mathrm{AP}$ of $\mathrm{AE}$ ringing counts is mainly governed by the crack closure stage of the rock. The $\mathrm{CP}$ of $\mathrm{AE}$ ringing counts corresponds to the elastic deformation stage of rock deformation. Over a relatively long duration, the magnitude of $\mathrm{AE}$ ringing counts remains small and in a stable range. This implies that there is no clear crack propagation during this period. Deformation energy does, however, continue to accumulate until failure occurs. During failure, the sample experiences plastic deformation and a period of sharp variations in principal stress. The $\mathrm{AE}$ ringing counts increase substantially compared with the $\mathrm{CP}$ state and reach a peak value, which indicates that the rock samples are experiencing rapid crack initiation and propagation (Figure 5(a)). Under triaxial compression, because of the confining pressure, the original cracks within the rock samples are compacted before axial differential stress is applied. Cracks are more effectively closed with fewer freezethaw cycles (Figures 5(b)-5(d)). AE ringing counts during $\mathrm{AP}$ and $\mathrm{CP}$ are relatively rare, and changes are not as clear. Furthermore, the active $\mathrm{AE}$ phenomenon at the initial loading stage does not occur substantially during triaxial compression. Notably, there are fewer ringing counts for the samples that underwent 60 freeze-thaw cycles than for the other samples. This may be related to the overall propagation of damage planes inside the rock due to the 60 freeze-thaw cycles, but this damage did not penetrate on a large scale. Consequently, the propagated damage planes were closed under the action of the confining pressure. In the initial stage of applying the deviation stress $\left(\sigma_{1}-\sigma_{3}\right)$, the sample produced fewer new fractures and thus fewer ringing counts were detected.

During triaxial compression experiments, the peak value of AE ringing counts mainly occurs during peak stress and 


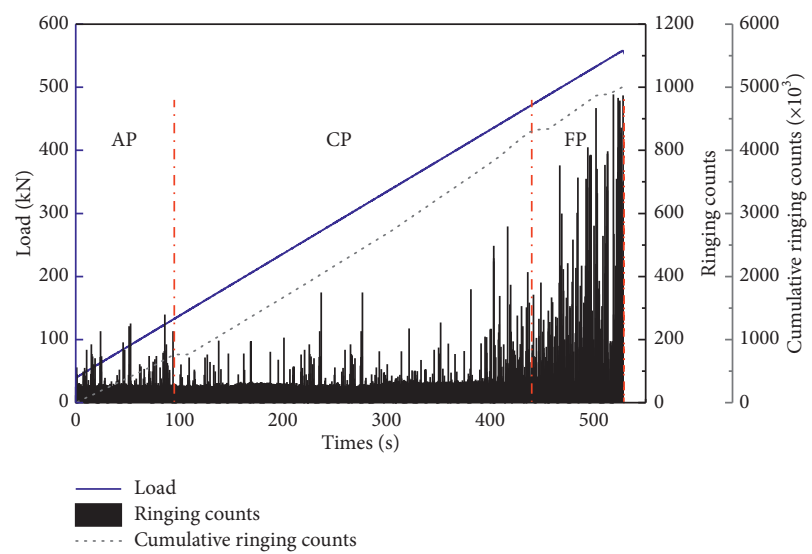

(a)

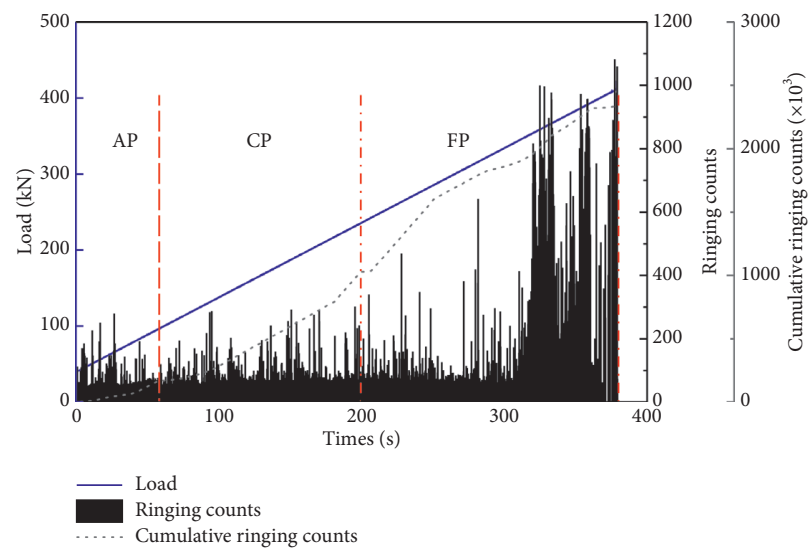

(c)

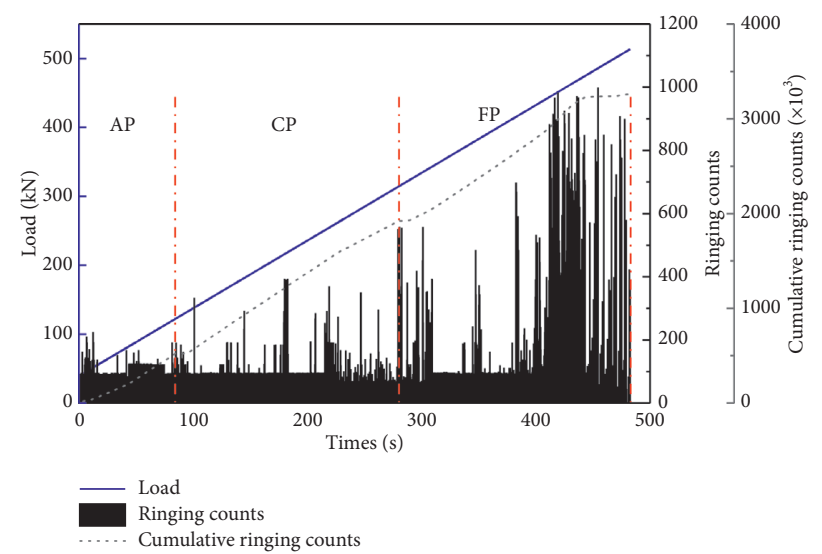

(b)

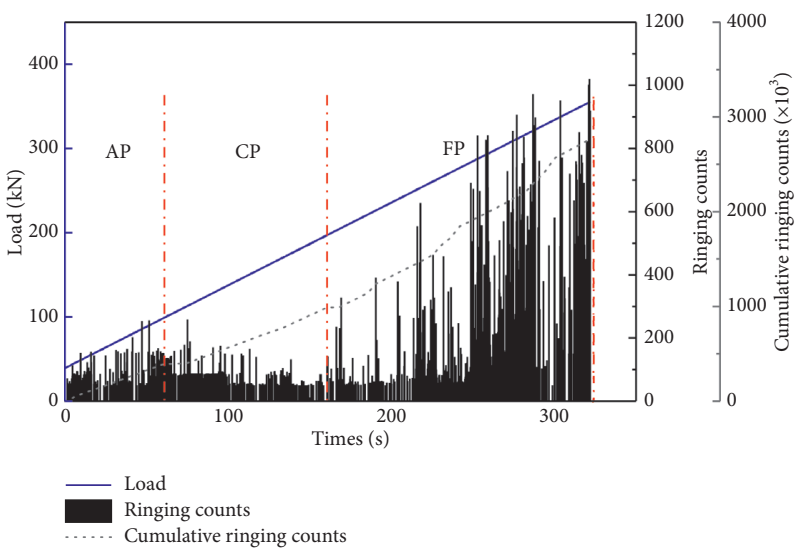

(d)

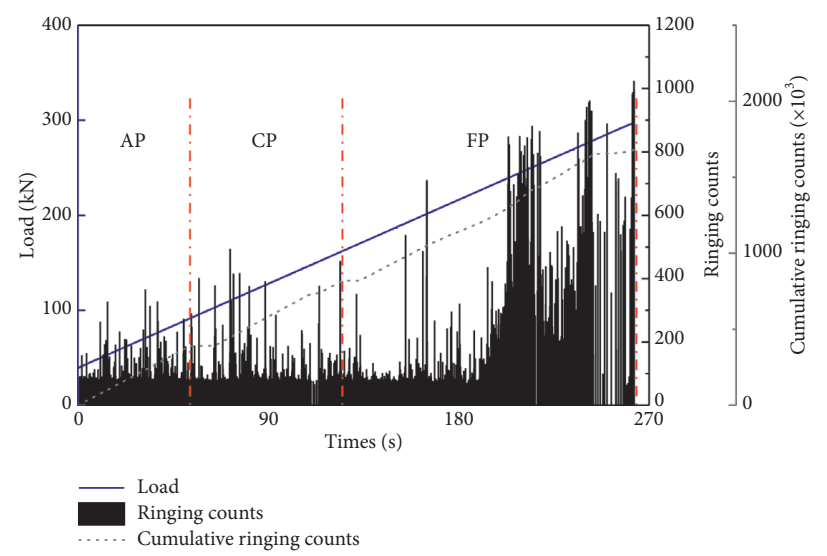

(e)

Figure 5: Relationship between load and time and ringing counts measured in granite samples that had undergone different numbers of freeze-thaw cycles under triaxial compression. (a) 0 freeze-thaw cycles, (b) 10 freeze-thaw cycles, (c) 30 freeze-thaw cycles, (d) 60 freezethaw cycles, and (e) 90 freeze-thaw cycles.

stress reduction and is well correlated with stress reduction. The main failure stage of rock is also the active stage of peak ringing counts, as shown in Figure 5; the $\mathrm{AE}$ ringing counts increase substantially at failure. For granite samples that have undergone a higher number of freeze-thaw cycles (Figures 5(c)-5(e)), the AE ringing counts increase significantly when the samples reach peak principal stress. When the load exceeds the peak value, the sample may present macro ruptures, and the $\mathrm{AE}$ ringing counts will reach maximum values.

3.4. AE Peak Frequency. The characteristics of the frequency spectrum of the AE signal generated by the rock can indicate the stress state, rock structure, and mechanical properties of the rock [33]. All AE waveform signals from loading to 
destruction of each sample were selected and performed fast Fourier transformation (FFT) on all waveforms from the time domain to the frequency domain. As a result, the peak frequency, defined as the frequency corresponding to the maximum amplitude in the spectrogram for each freeze-thaw cycle at different moments during the loading process was obtained (Figure 6).

Figure 6 shows that the peak frequency of signals from all samples occurs in two main distribution bands, at high and low frequencies. As shown in Figure 6(a), there are fewer AE events in the granite sample that did not undergo freeze-thaw cycling (group A) during the initial period of compression, and peak frequencies remain in the two different frequency bands, one low-frequency window (with peak frequency around $40 \mathrm{kHz})$ and one high-frequency window $(\sim 165 \mathrm{kHz})$. When the sample progresses into the stage of stable crack propagation, the $\mathrm{AE}$ events begin to increase and remain in a stable range. The peak frequency of the signal at this stage is distributed in two frequency bands, $30-60 \mathrm{kHz}$ and $150-180 \mathrm{kHz}$. During the entire loading process, AE signals are frequent and the peak frequency increases until the rock is destroyed. The peak frequency is distributed in two frequency bands, $25-75 \mathrm{kHz}$ and $140-200 \mathrm{kHz}$. Figure 6(b) shows data for the samples that underwent ten freeze-thaw cycles (group B). These data show that the peak frequencies of AEs during initial loading are mainly distributed in the ranges $25-70 \mathrm{kHz}$ and $125-170 \mathrm{kHz}$. When the load increases, the peak frequency distribution increases to $25-75 \mathrm{kHz}$ and $125-175 \mathrm{kHz}$, and the peak frequency distribution of $\mathrm{AE}$ signal narrows. When the sample is loaded to peak axial stress, the AE signals clearly aggregate, and the peak frequency occurs in bands from $25-75 \mathrm{kHz}$ and $125-190 \mathrm{kHz}$. Compared with samples in group $\mathrm{A}$, the peak frequency of $\mathrm{AE}$ signals in this group is relatively sparse and scattered, and while the overall peak frequency also increases with loading time, the trend is slower. Figure 6(c) shows data from group C, samples that have undergone 30 freeze-thaw cycles. Peak frequencies of AE are distributed in bands $30-40 \mathrm{kHz}$ and $150-175 \mathrm{kHz}$ during the initial compression period. When the sample reaches the macroscopic failure stage, the number of AE events increases sharply and the peak frequency of the added events is concentrated at $30-60 \mathrm{kHz}$ and $135-180 \mathrm{kHz}$. When the sample reaches peak axial compression stress, peak frequency is in the range of $30-75 \mathrm{kHz}$ and $140-185 \mathrm{kHz}$. Figure 6(d) shows data for samples after 60 freeze-thaw cycles (group D). There are fewer AE events, and the peak frequency distribution is larger, in the range of $30-50 \mathrm{kHz}$ and $150-180 \mathrm{kHz}$. This phenomenon changes after the initiation of macrocracks. The number of triggering events clearly increases at the stage of microcrack initiation, but the peak frequency distribution remains in the same interval. The number of $\mathrm{AE}$ events again increases sharply when the sample is destroyed; the peak frequency distribution in this stage is $25-60 \mathrm{kHz}$ and $140-190 \mathrm{kHz}$. Figure 6(e) shows data from group E, samples that have undergone 90 freeze-thaw cycles. The peak frequency range of $\mathrm{AE}$ signals is narrow, distributed in bands $25-60 \mathrm{kHz}$ and $135-175 \mathrm{kHz}$ during the initial loading stage. The high- and low-frequency bands are relatively dispersed, but the frequency range does not change substantially as loading progresses. The peak frequency is distributed in bands $20-70 \mathrm{kHz}$ and $135-190 \mathrm{kHz}$.

\section{Discussion}

The variation of $\mathrm{AE}$ ringing counts of granite samples under triaxial compression that have undergone freeze-thaw cycles has three stages: AP, CP, and FP. This is similar to that of a uniaxial compression experiment [27]. Although crack closure of the granite samples occurs primarily from the initiation of loading to the loading state $\sigma_{1}=\sigma_{3}$, from the data, it is clear that crack closure continues when $\sigma_{1}-\sigma_{3} \geq 0$ (Figure 4). Compared with uniaxial compression, the AE signals generated during triaxial compression are weaker and more scattered. This indicates that triaxial compression results in fewer compressed voids within the sample or a smaller degree of closure of primary local cracks. In the uniaxial compression experiments of the same batch of granite after freeze-thaw cycles, AE is very active at the beginning of loading (i.e., AP) [27]. In the absence of confining pressure, the peak value of $\mathrm{AE}$ ringing counts during the $\mathrm{CP}$ is close to the peak value of $\mathrm{AE}$ ringing counts throughout the duration of test process. This becomes increasingly true with the increasing number of freeze-thaw cycles. For the samples that underwent 90 and 120 freeze-thaw cycles, there is no difference in the AE ringing counts between AP and CP. Consequently, the CP becomes smaller in relation to the other periods. The AE phenomenon during compression is closely related to the number of freezethaw cycles. Because of the irreversible damage caused by the freeze-thaw process, during compression, microcracks develop and propagate, which increases porosity. At the beginning of stress loading, the axial stress has little effect on the sample, and there are few new cracks. Therefore, the fewer freeze-thaw cycles the rock has endured; the longer the duration of the $\mathrm{CP}$ (Figure 7). During compression, AEs are the most active during macroscopic failure. At this stage, the primary fracturing of the rock samples has occurred, and there are many microcracks. The crack propagation is unstable, which results in an irregular distribution of AE ringing counts. As shown in Figure 6, samples that have endured more freeze-thaw cycles have a longer failure stage relative to the other stages, as well as more frequent and pronounced AEs.

AE peak frequency occurs mainly in high-frequency and low-frequency bands, and the peak frequency data points comprising the two frequency bands diverge at a specific frequency range. This is consistent with the results of a previous study, which found that the AE signal in marble has dual dominant frequencies [34]. Deng et al. [34] also showed that this phenomenon can be most likely attributed to two cracking types, that is, the lower peak frequency corresponds to the microtension cracking, while the higher peak frequency to the microshear cracking. However, there is no clear evidence to distinguish between the tension and shear cracking using the direct tensile test, Brazilian test, or uniaxial compression test. It seems reasonable that this dual dominant distribution may be ascribed to the different dimensions of the opening and closing of existing cracks, that is, a larger source dimension leads to a decrease in peak 


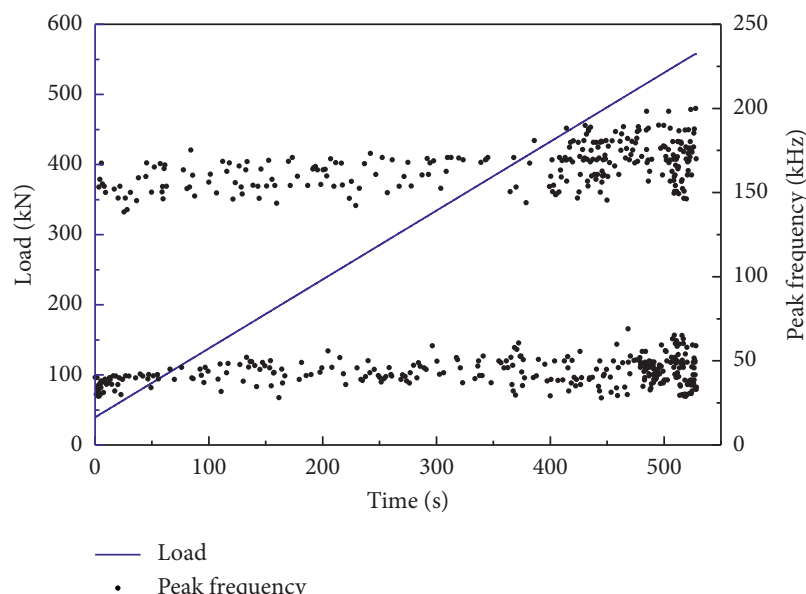

(a)

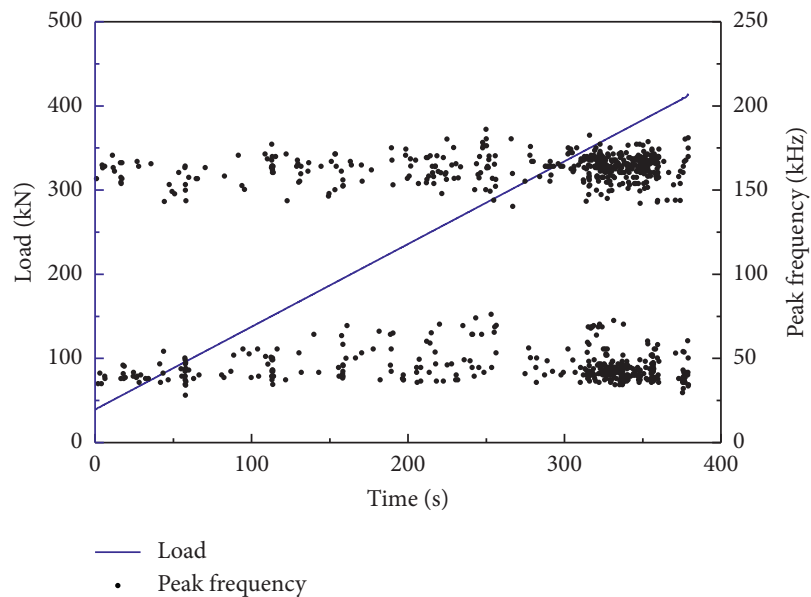

(c)

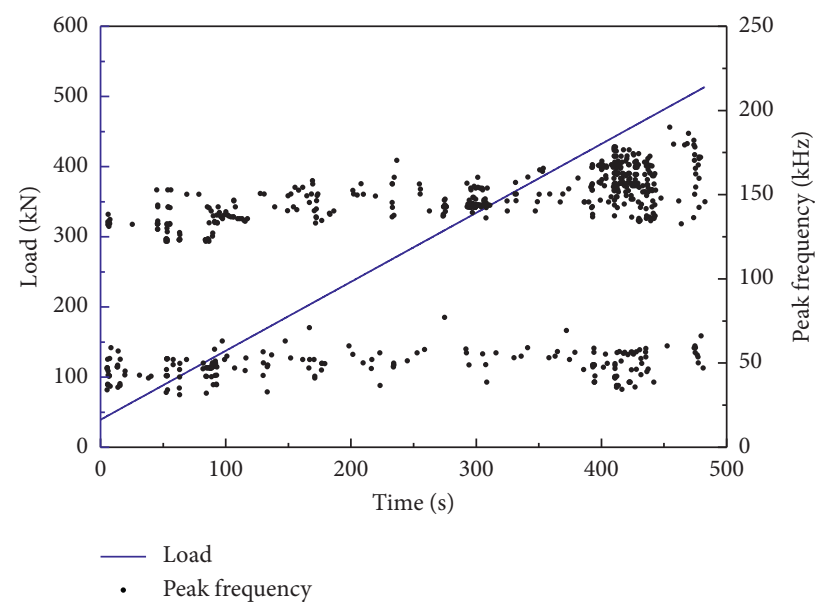

(b)

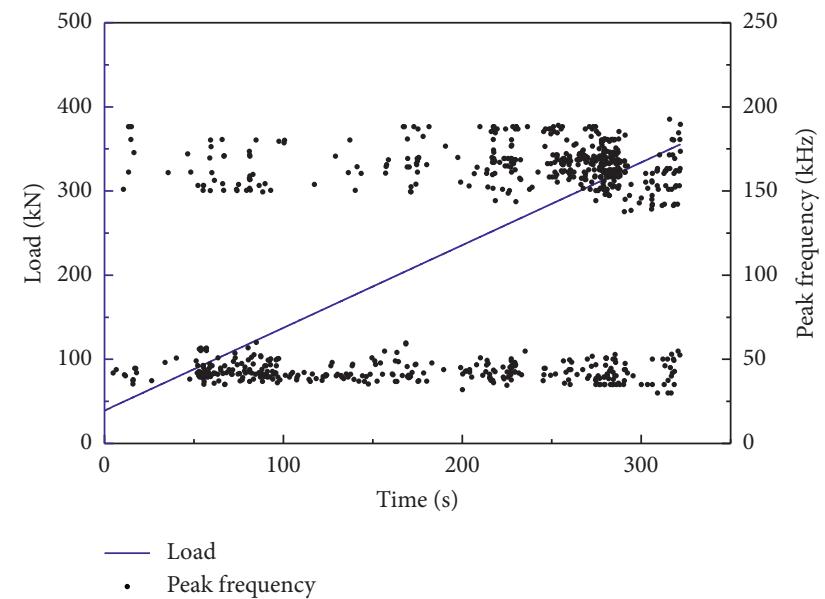

(d)

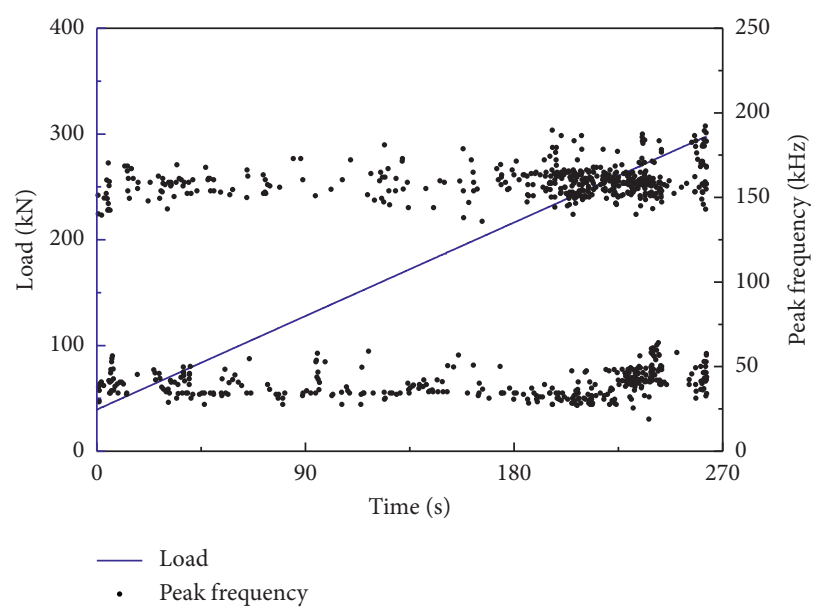

(e)

Figure 6: Relationship between load and time and peak AE frequency of each group of granite samples under triaxial compression. (a) 0 freeze-thaw cycles, (b) 10 freeze-thaw cycles, (c) 30 freeze-thaw cycles, (d) 60 freeze-thaw cycles, and (e) 90 freeze-thaw cycles.

frequency, and vice versa, same as that reported by Ohnaka et al. [35] and Cai et al. [36]. This indicates that the variability of microfracture scales is in a specific range. The peak frequency distributions of both high- and low-frequency bands increase with increasing load time, and the trend becomes less clear with an increasing number of freeze-thaw cycles. This implies that with an increasing magnitude of stress, the degree of compaction of the rock increases slowly. Hence, the frequency of AE signals increases slowly until the rock sample is destroyed. The freeze-thaw damage results in 


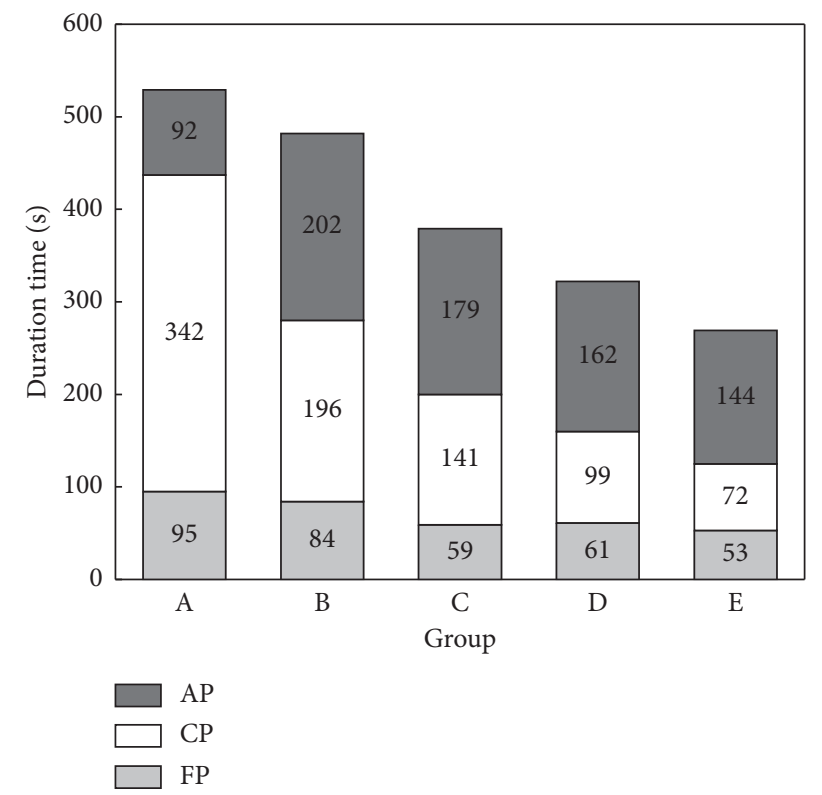

Figure 7: Proportion of the duration of the three stages for each group.
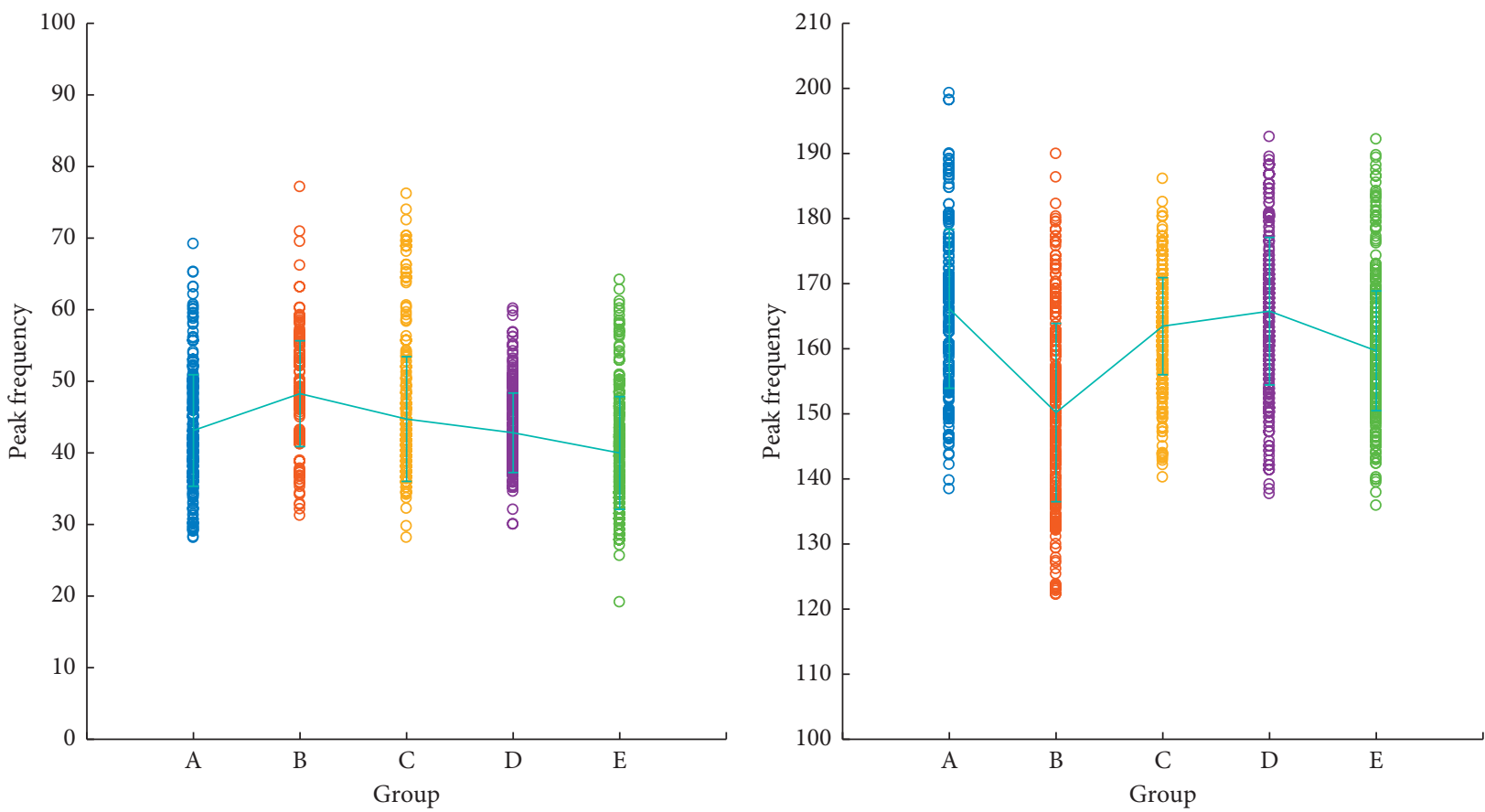
○ A
$\circ \mathrm{B}$
$\circ \mathrm{C}$
- D
- E
I Error bar

(a)
$\circ \mathrm{A}$
○ $\mathrm{B}$
- D
- E
I Error bar

(b)

FiguRE 8: Variation trend of the peak frequency mean value for each group (indicated by the solid cyan line). (a) The low-frequency bands and (b) the high-frequency bands.

the relaxation of the rock fabric, which changes the effect of stress compaction. The peak frequency of AEs increases with increasing load, but this trend slows down as the number of freeze-thaw cycles increases. With the increasing number of freeze-thaw cycles, the peak $\mathrm{AE}$ frequency becomes less disordered and is distributed in narrower bands. The data presented in Figure 8 show that the variation of the peak frequency mean value for each group shows a different trend. The peak frequency mean value in low-frequency bands approximately shifts from high to low with an 
increasing number of freeze-thaw cycles. However, there seems to be no apparent variation law governing the highfrequency mean value. Therefore, the freeze-thaw cycles perhaps primarily influence the propagation of macroscopic cracks within the granite sample, which results in a lower AE signal frequency.

The density distribution of AE signals is indicative of the number of micro-cracks in the rock samples during loading. The most intensive distribution of $\mathrm{AE}$ signals occurs near the end of loading period, indicating the frequent onset, development, and propagation of microfractures in the rock samples. When these microcracks in the rock sample have fully developed and propagated, the rock is approaching macrofailure. An increase of AE events occurs at the macrofailure stage of the sample, when the internal microcracks have developed into primary fractures, and the sample reached peak axial compressive strength. An increasing number of $\mathrm{AE}$ signal events can therefore be regarded as the precursor phenomenon of rock failure. Furthermore, an increasing number of $\mathrm{AE}$ events are related to freeze-thaw cycles. With an increase of freezethaw cycles, the number of $\mathrm{AE}$ events triggered before the main fracture of rock increases. Combined with monitoring rock mass stability, a sudden change of AE characteristics or the phenomenon of a relatively quiet period appearing before rock mass failure can be used as a reference for rock mass stability monitoring and disaster prediction. The number of AE events increases markedly when the principal stress of the samples reaches its peak value, which may correspond to a change from isolated dilatant cracking to the rapid crack linkage and coalescence [37].

Although the influence of freeze-thaw cycling on the $\mathrm{AE}$ characteristics of granite samples under triaxial compression is investigated, these data are not sufficient for a comprehensive evaluation of the triaxial compression with $20 \mathrm{MPa}$ confining pressure. In addition, the granite samples used here have inevitable differences in composition and texture. More experimental work with different confining pressures should be considered in future studies.

\section{Conclusions}

In this paper, granite samples collected from a cold region were subjected to different degrees of freeze-thaw cycling and $\mathrm{AE}$ tests under triaxial compression were performed. The influence of freeze-thaw cycling on the AE characteristics of granite samples under triaxial compression is summarized as follows:

(1) With an increasing number of freeze-thaw cycles, the P-wave velocity and the peak strength of triaxial compression of granite show a clear decreasing trend. The more the freeze-thaw cycles, the higher the rate of reduction of wave velocity, and the lower the peak strength of triaxial compression, the stronger the compaction phenomenon.

(2) During triaxial compression, the change of $\mathrm{AE}$ ringing counts with time can be divided into three stages: abrupt period, calm period, and failure period. The change of $\mathrm{AE}$ signals of granite samples exposed to different numbers of freeze-thaw cycles is similar. With more freeze-thaw cycles, the failure period is longer in relation to the entire loading process, and $\mathrm{AE}$ signals are more frequent and clearer.

(3) The AE signal frequency of freeze-thaw damaged granite under triaxial compression occurs in two main frequency bands. The peak frequency distribution of $\mathrm{AE}$ signals in both the high and low frequency bands increases with increasing load time. The trend is not clear with an increasing number of freeze-thaw cycles. With the increase of freeze-thaw cycles, the $\mathrm{AE}$ peak frequency converges from scattered disorder to a dominant frequency band and the peak frequency distribution mean value overall changes from higher frequency to lower frequency in low-frequency bands.

(4) The increase of AE peak frequency can be regarded as a precursor to rock fracture, and the increase of the number of events is related to freeze-thaw cycling. More freeze-thaw damage triggers a higher number of peak frequency events before rock failure.

\section{Data Availability}

The data used to support the findings of this study are available from the corresponding author upon request.

\section{Conflicts of Interest}

The authors declare that they have no conflicts of interest regarding the publication of this paper.

\section{Acknowledgments}

This research was funded by the Langfang Science and Technology Support Plan Project (grant number 2020013147) and the National Natural Science Foundation of China (grant number 41807270). We thank Dr. Katherine Armstrong for her proofreading and constructive suggestions. We would like to express our deep appreciation to Dr. Chuanbin Zhu for his discussion and assistance.

\section{References}

[1] S. Q. Qin, An Introduction to Acoustic Emission (AE) Techniques in Rocks, pp. 1-2, Southwest Jiaotong University Press, Chengdu, China, 1993.

[2] Y. Chen, "Application of AE techniques in rock mechanics," Geophysical Journal International, vol. 20, pp. 312-322, 1977.

[3] Z. L. Zhou, J. Zhou, L. J. Dong, X. Cai, Y. C. Rui, and C. T. Ke, "Experimental study on the location of an acoustic emission source considering refraction in different media," Scientific Reports, vol. 7, no. 1, p. 7472, 2017.

[4] M. Abdelrahman, M. Elbatanouny, K. Dixon, M. Serrato, and P. Ziehl, "Remote monitoring and evaluation of damage at a decommissioned nuclear facility using acoustic emission," Applied Sciences, vol. 8, no. 9, p. 1663, 2018. 
[5] Y. Chen, Y. Yang, F. Gao, and X. Zhang, "Researches on damage evolution and acoustic emission characteristics of rocks," Advances in Civil Engineering, vol. 2018, no. 4, 7 pages, Article ID 3108065, 2018.

[6] P. Ganne, A. Vervoort, and M. Wevers, "Quantification of pre-peak brittle damage: correlation between acoustic emission and observed micro-fracturing," International Journal of Rock Mechanics and Mining Sciences, vol. 44, no. 5, pp. 720-729, 2007.

[7] X. Ni, X. Shen, Z. Zhu et al., "Mechanical and acoustic emission characteristics of sandstone through triaxial unloading test after cyclic freezing-thawing treatment," $\mathrm{Ad}$ vances in Civil Engineering, vol. 2020, Article ID 7150536, 12 pages, 2020.

[8] M. V. M. S. Rao and Y. V. Ramana, "A study of progressive failure of rock under cyclic loading by ultrasonic and AE monitoring techniques," Rock Mechanics and Rock Engineering, vol. 25, no. 4, pp. 237-251, 1992.

[9] X. Lei, K. Kusunose, M. V. M. S. Rao, O. Nishizawa, and T. Satoh, "Quasi-static fault growth and cracking in homogeneous brittle rock under triaxial compression using acoustic emission monitoring," Journal of Geophysical Research: Solid Earth, vol. 105, no. B3, pp. 6127-6139, 2000.

[10] H.-Q. Shuang, S.-G. Li, L. Liu, G.-F. Liu, and K.-I. Song, "Use of acoustic emission for the detection of brittle rock failure under various loading rates," Advances in Civil Engineering, vol. 2018, Article ID 5735139, 9 pages, 2018.

[11] D. Luo, G. Su, and G. Zhang, "True-triaxial experimental study on mechanical behaviours and acoustic emission characteristics of dynamically induced rock failure," Rock Mechanics and Rock Engineering, vol. 53, no. 3, pp. 1205-1223, 2019.

[12] T. Shiotani, M. Ohtsu, and K. Ikeda, "Detection and evaluation of AE waves due to rock deformation," Construction and Building Materials, vol. 15, no. 5-6, pp. 235-246, 2001.

[13] P. G. Ranjith, D. Jasinge, S. K. Choi, M. Mehic, and B. Shannon, "The effect of $\mathrm{CO}_{2}$ saturation on mechanical properties of Australian black coal using acoustic emission," Fuel, vol. 89, no. 8, pp. 2110-2117, 2010.

[14] V. G. Ruiz, R. A. Rey, C. Clorio, L. M. Suarez, and L. Calleja, "Characterization by computed X-ray tomography of the evolution of the pore structure of a dolomite rock during freeze-thaw cyclic tests," Physics and Chemistry of the Earth, vol. 24, no. 7, pp. 633-637, 1999.

[15] D. T. Nicholson, F. H. Nicholson, Physical deterioration of sedimentary rocks subjected to experimental freeze-thaw weathering," Earth Surface Processes and Landforms, vol. 25, no. 12, pp. 1295-1307, 2000.

[16] M. Mutlutük, R. Altindag, and G. TürK, “A decay function model for the integrity loss of rock when subjected to recurrent cycles of freezing-thawing and heating-cooling," International Journal of Rock Mechanics and Mining Sciences, vol. 41, no. 2, pp. 237-244, 2004.

[17] M. H. Ghobadi and R. Babazadeh, "Experimental studies on the effects of cyclic freezing-thawing, salt crystallization, and thermal shock on the physical and mechanical characteristics of selected sandstones," Rock Mechanics and Rock Engineering, vol. 48, no. 3, pp. 1001-1016, 2015.

[18] C. Walbert, J. Eslami, A.-L. Beaucour, A. Bourges, and A. Noumowe, "Evolution of the mechanical behaviour of limestone subjected to freeze-thaw cycles," Environmental Earth Sciences, vol. 74, no. 7, pp. 6339-6351, 2015.

[19] D. E. Sarici and E. Ozdemir, "Determining point load strength loss from porosity, Schmidt hardness, and weight of some sedimentary rocks under freeze-thaw conditions," Environmental Earth Sciences, vol. 77, no. 3, p. 62, 2018.

[20] S. Z. S. Mousavi, H. Tavakoli, P. Moarefvand, and M. Rezaei, "Micro-structural, "petro-graphical and mechanical studies of schist rocks under the freezing-thawing cycles," Cold Regions Science and Technology, vol. 174, 2020.

[21] C. Liu, H. W. Deng, X. M. Chen, D. J. Xiao, and B. Li, “"Impact of rock samples size on the microstructural changes induced by freeze-thaw cycles," Rock Mechanics and Rock Engineering, vol. 53, pp. 5293-5300, 2020.

[22] C. Liu, J. Deng, S. Yu, P. Li, and Y. Lin, "Effect of freezing and thawing on microstructure damage and dynamic flexural tension of granite," Rock Mechanics and Rock Engineering, vol. 53, no. 8, pp. 3853-3858, 2020.

[23] H. Jia, S. Ding, Y. Wang, F. Zi, Q. Sun, and G. S. Yang, “An NMR-based investigation of pore water freezing process in sandstone," Cold Regions Science and Technology, vol. 168, 2019.

[24] L. Qin, S. G. Li, C. Zhai et al., "Changes in the pore structure of lignite after repeated cycles of liquid nitrogen freezing as determined by nitrogen adsorption and mercury intrusion," Fuel, vol. 267, p. 267, 2020.

[25] W. D. Zhao, T. Goto, and W. B. Du, "Study on deteriorating mechanism of riprap material under freezing and thawing condition," Chinese Journal of Geotechnical Engineering, vol. 24, pp. 663-666, 2002.

[26] G. Wu, G. L. He, L. Zhang, and Y. Qiu, "Experimental study on cycles of freezing-thawing marble," Chinese Journal of Geotechnical Engineering, vol. 25, pp. 2930-2938, 2006.

[27] Z. D. Su, J. Z. Sun, J. Xia, and C. L. Wu, "Experimental research of the effect of freezing-thawing cycles on acoustic emission (AE) characteristics of granite," Chinese Journal of Rock Mechanics and Engineering, vol. 38, pp. 865-874, 2019.

[28] C. E. Fairhurst and J. A. Hudson, "Draft ISRM suggested method for the complete stress-strain curve for intact rock in uniaxial compression," International Journal of Rock Mechanics and Mining Sciences \& Geomechanics, vol. 36, no. 3, pp. 281-289, 1999.

[29] Y. Wu, S. Gu, G. Zhao, and S. L. Li, "Damage assessment of the in-service brick masonry structure using acoustic emission technique," Materials and Structures, vol. 53, no. 2, pp. 1-10, 2020.

[30] J. Ruedrich, D. Kirchner, and S. Siegesmund, "Physical weathering of building stones induced by freeze-thaw action: a laboratory long-term study," Environmental Earth Sciences, vol. 63, no. 7-8, pp. 1573-1586, 2011.

[31] J. Park, C.-U. Hyun, and H.-D. Park, "Changes in microstructure and physical properties of rocks caused by artificial freeze-thaw action," Bulletin of Engineering Geology and the Environment, vol. 74, no. 2, pp. 555-565, 2015.

[32] X. Tan, W. Chen, J. Yang, and J. Cao, "Laboratory investigations on the mechanical properties degradation of granite under freeze-thaw cycles," Cold Regions Science and Technology, vol. 68, no. 3, pp. 130-138, 2011.

[33] Y. B. Zhang, P. Liang, X. X. Liu, S. J. Liu, and B. Z. Tian, "Experimental study on precursor of rock burst based on acoustic emission signal dominant-frequency and entropy," Chinese Journal of Geotechnical Engineering, vol. 34, pp. 2959-2967, 2015.

[34] J. H. Deng, L. R. Li, F. Chen, J. F. Liu, and J. Yu, "Twin-peak frequencies of acoustic emission (AE) due to the fracture of marble and their possible mechanism," Journal of Sichuan University, vol. 50, pp. 12-17, 2018. 
[35] M. Ohnaka and K. Mogi, "Frequency characteristics of acoustic emission in rocks under uniaxial compression and its relation to the fracturing process to failure," Journal of Geophysical Research Solid Earth, vol. 87, no. B5, pp. 3873-3884, 1982.

[36] M. Cai, P. K. Kaiser, H. Morioka et al., "FLAC/PFC coupled numerical simulation of AE in large-scale underground excavations," International Journal of Rock Mechanics and Mining Sciences, vol. 44, no. 4, pp. 550-564, 2007.

[37] M. R. Ayling, P. G. Meredith, and S. A. F. Murrell, "Microcracking during triaxial deformation of porous rocks monitored by changes in rock physical properties, II. Pore volumometry and acoustic emission measurements on water-saturated rocks," Tectonophysics, vol. 245, no. 3-4, pp. 205-221, 1995. 